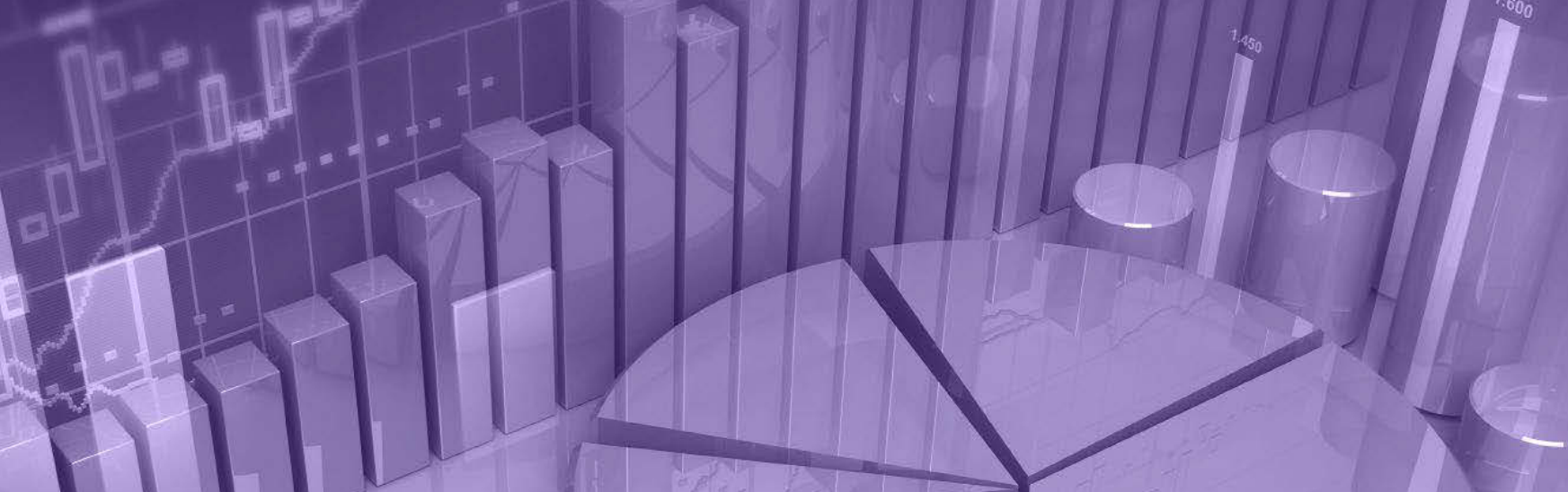

\title{
Credit Spreads and Equity Volatility during Periods of Financial Turmoil
}

\section{By Katrin Gottschalk}

Katrin Gottschalk is a Senior Lecturer in Finance at the Auckland University of Technology, New Zealand

We present a joint analysis of the term structure of credit default swap (CDS) spreads and the implied volatility surface for the United States and five European countries from 20072012, a sample period covering both the Global Financial Crisis (GFC) and the European debt crisis. We analyze to which extent effective cross-hedges can be performed between the CDS and equity derivatives markets during these two crises. We find that during a global crisis a breakdown of the relationship between credit risk and equity volatility may occur, jeopardizing any cross-hedging strategy, which happened during the GFC. Thisstands in sharp contrast to the more localized European debtcrisis, during which this fundamental relationship was preserved despite turbulent market conditions for both the CDS and volatility markets. Keywords: Credit Default Swap, Term Structure, Implied Volatility Surface, Factor Decomposition, Market Linkages, Cross-Hedging

\section{Introduction}

Merton (1974) stresses the intrinsic relationship between credit spreads and equity volatility. A plethora of articles have studied this interrelation since, measuring credit spreads with yield spreads computed from bonds and equity volatility with mean squared returns. More recently, the rapid development of the credit default swap (CDS) market has provided convenient products to extract credit risk. Furthermore, the availability of implied volatility has led to a preferable alternative way to quantify equity volatility because option volatility is considered "forward looking". Therefore, over the last years many studies have focused on the interaction between CDS spreads and implied volatility. A first set of papers analyses the relation between the 5-year CDS spread and the at-the-money (ATM) 1-month implied volatility, see Benkert (2004) and Forte and Pena (2009), for example.

This kind of study was extended by considering other parts of the implied volatility surface (beyond the 1-month ATM volatility) and/or the term structure of CDS spreads (beyond the 5-year CDS spread). Cao, Yu and Zhong (2010) analyse the 5-year CDS spread along with the atthe-money implied volatility and the implied volatility skew (see also Cao, Yu and Zhong, 2011), where the implied volatility skew can be defined as either the slope of the ATM smile or the difference between in-the-money and out-ofthe-money implied volatility, for a given time to maturity. Cremers, Driessen, Maenhout and Weinbaum (2008) analyse the impact of both implied volatility (ATM) and the implied volatility skew on corporate bond credit spreads (long and short maturities) and find that these variables have strong explanatory power. Carr and WU (2010) find a significant correlation between the level and the skew of the smile and the average (along the term structure axis) of the CDS spread on corporate data. Hui and Chung (2011) study the 10-delta dollar-euro implied volatility in relation to the 5-year sovereign CDS spread. Han and Zhou (2011) find that the term structure of CDS spreads explains log stock returns; hence, the slope of the CDS curve contains relevant information for the stock dynamics.

These works have led to the development of joint models for the equity derivatives and CDS markets. Along this line, Carr and Wu $(2007,2010)$ propose a joint model for the term structure of CDS spreads and options, whilst Carverhill and Luo (2011) analyse the interaction between the factors of a 
model calibrated on collateralized debt obligations (CDOs) and the factors driving the implied volatility surface. CollinDufresne, Goldstein and Yang (2012) propose a joint analysis of index options and CDOs. Da Fonseca and Gottschalk (2013) jointly analyse the entire implied volatility surface and the entire term structure of CDS spreads, using factor decompositions, and perform a cross-hedging analysis between the two markets.

In this article, we analyse how crises affect the intrinsic relationship that ties together the CDS and equity derivatives markets. Using a sample from May 2007 to September 2012 for major index options (S\&P500, CAC40, FTSE100, DAX30, IBEX35, MIB40) and the term structure of CDS spreads computed for each country, we analyse the joint evolution of these two markets. We find that during the Global Financial Crisis (2007-2009) the relation between the credit and volatility markets breaks down although the crisis affects both of them. The results are different beyond 2009, during the European debt crisis, when the relationship between the markets is preserved although the European countries are affected very differently by the crisis. As a result, we conclude that there can be a breakdown of the credit-volatility relationship during global crises, which jeopardizes the effectiveness of cross-hedges between credit and equity instruments. During the GFC, this problem could have been overcome by performing a hedge within the same type of market, but across different geographic locations (i.e. European CDS with US CDS or European volatility with US volatility).

The main results can be summarised as follows. First, we show that the simple framework proposed in Da Fonseca and Gottschalk (2013) allows us to perform a reasonably effective cross-hedge between the CDS and equity derivatives markets. Second, we illustrate the fact that the relationship between the two markets can break down during a global crisis. In order to perform an effective hedge the cross-hedging position should be completed with a position on a similar product. Third, from a regulatory point of view our research underlines the claim for more stringent provisioning of hedgeable claims to cope with systemic risk.

\section{Data}

A credit default swap (CDS) is a credit derivative contract between two counterparties that essentially provides insurance against the default of an underlying entity. In a CDS, the protection buyer makes periodic payments to the protection seller until the occurrence of a credit event or the maturity date of the contract, whichever is first. The premium paid by the buyer is denoted as an annualized spread in basis points and referred to as CDS spread. If a credit event (default) occurs on the underlying financial instrument, the buyer is compensated for the loss incurred as a result of the credit event, i.e. the difference between the par value of the bond and its market value after default.

Our dataset uses credit default swaps on corporate bonds and comprises the evolution of the term structure of CDS spreads for five European countries: the United Kingdom, Germany, France, Italy, and Spain. We collect daily time series from Markit at maturities of $0.5,1,2,3,5$, 7, and 10 years from May 23, 2007 to September 17, 2012. We take non-sovereign entities from all sectors; the CDSs are written on senior unsecured debt and denominated in Euro. For each country and each maturity we average the individual CDS spreads. For comparison purposes, we also report the North American benchmark CDS index CDX. NA.IG. For this index, for each maturity we average among the 125 entities that constitute the index. As the time period investigated spans both the Global Financial Crisis (GFC) and the European debt crisis, we split the full sample period into two subsamples for all our analyses. The first subsample (May 23, 2007 - December 31, 2009) contains the US credit crunch and the GFC; the second subsample (January 1, 2010 - September 17, 2012) is more tranquil for most countries, with the exception of Spain (and also Italy), where the turbulences of the European debt crisis are clearly visible in CDS levels.

Figures 1-4 reflect the turmoil of the GFC from mid-2007 onwards, with CDS levels peaking at over 700 basis points in most countries around the default of Lehman Brothers (September 2008). During this period of hefty turbulence the term structure of CDS spreads becomes inverted. While CDS spreads come down in mid-2009 and the term structure returns to a normal positively-sloped shape, the onset of the European debt crisis is visible in the European markets from mid-2010 onwards when CDS prices start to rise again. While we observe moderate increases in the price of credit protection for corporates in France (and Germany), CDS levels in Spain (and Italy) show dramatic increases. 
Figure 1. Term structure of CDS spreads for the United States

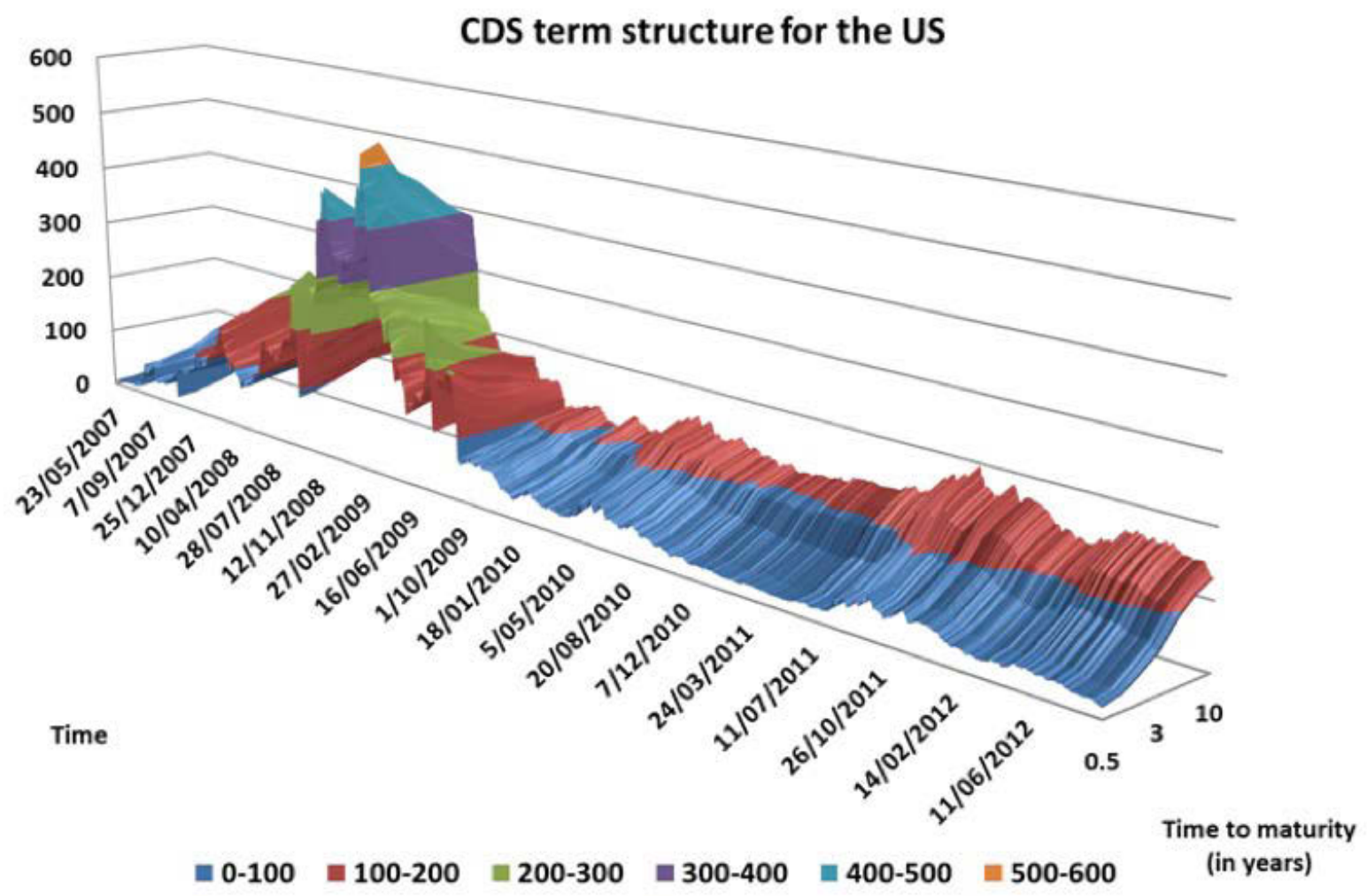

Figure 2. Term structure of CDS spreads for the United Kingdom

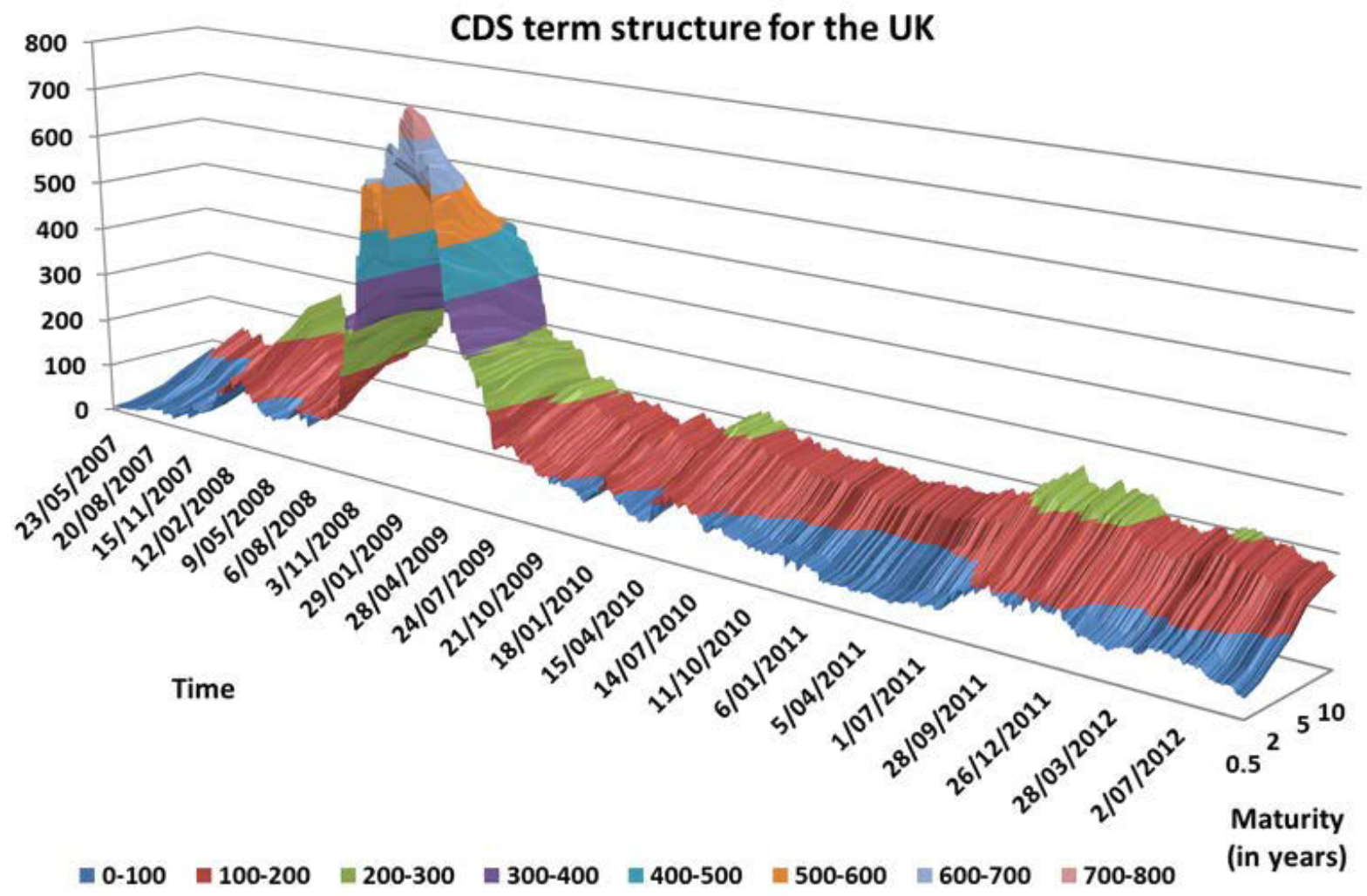


Figure 3. Term structure of CDS spreads for France

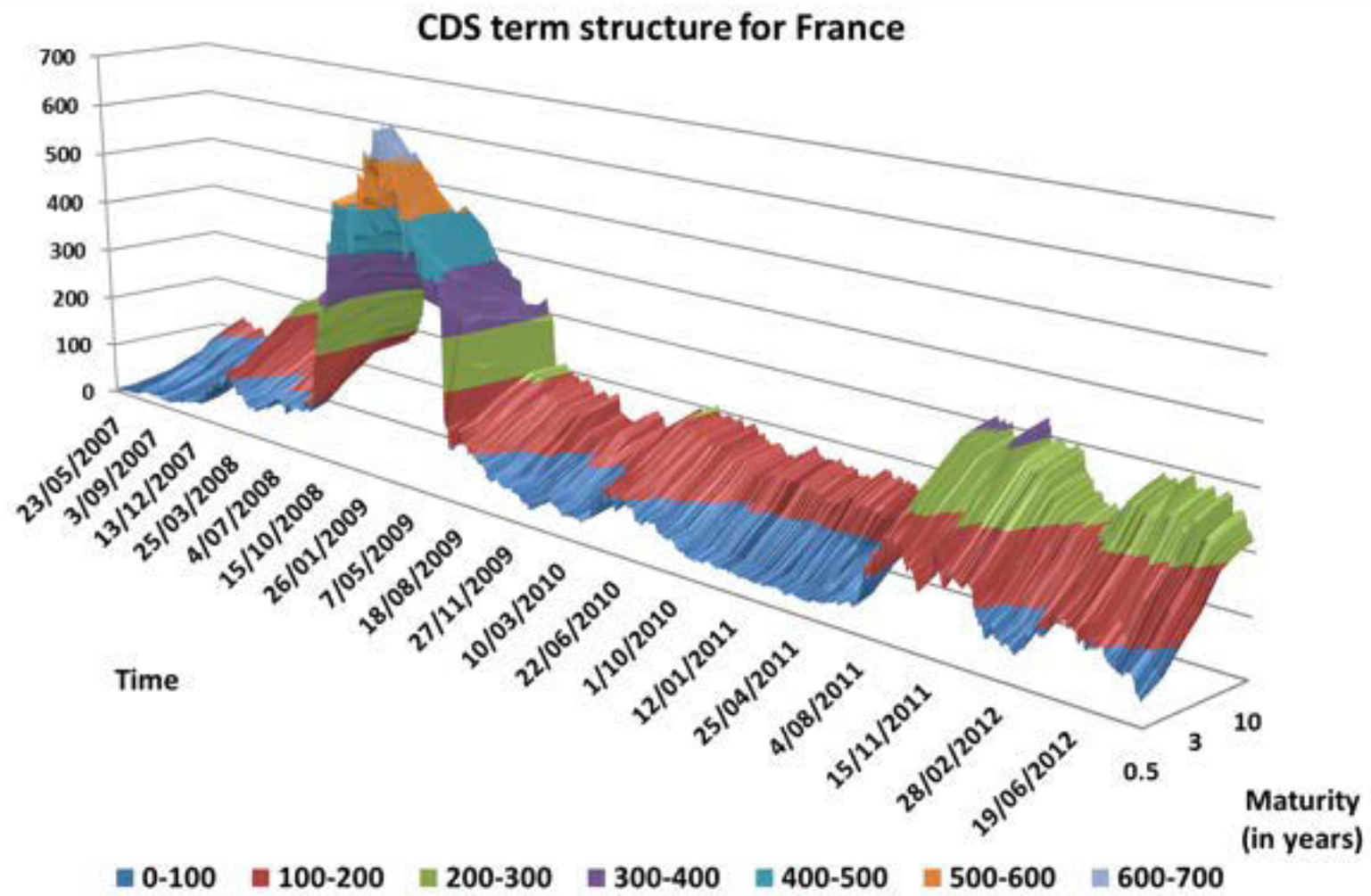

Figure 4. Term structure of CDS spreads for Spain

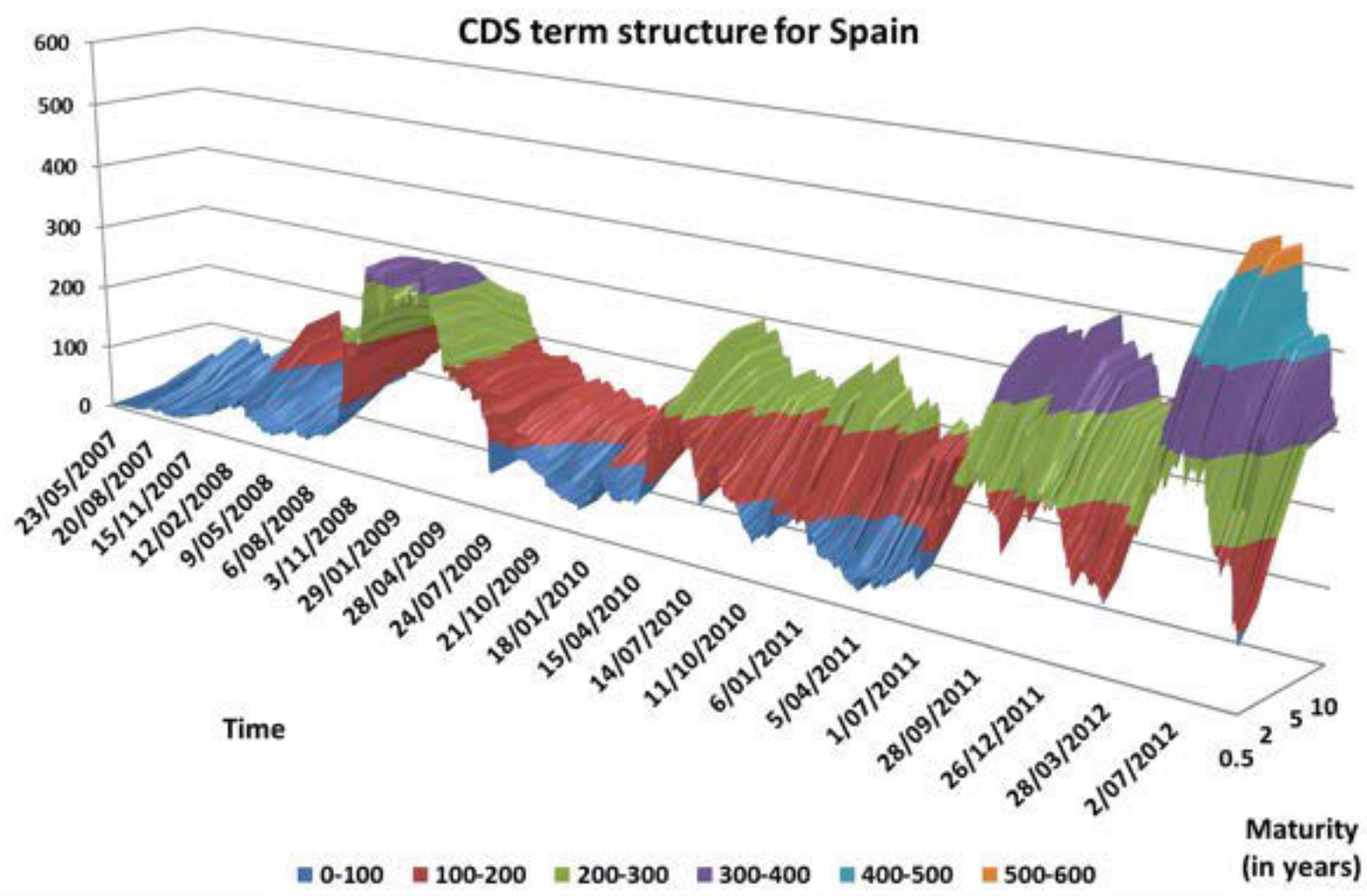


The first subsample (May 2007 - December 2009) displays significantly higher CDS spreads and elevated volatility for most countries due to the GFC. Moreover, the term structure is almost flat and at times even inverted, mainly because the very short-term end of the curve increased significantly during that period. This stands in stark contrast to the second subsample (January 2010 -September 2012). The steeper slope of the term structure is accompanied by lower CDS spread levels and drastically reduced volatility. Spain and Italy are the exceptions where CDS spreads reach higher levels during the second subsample, which includes the European debt crisis.
The implied volatility surfaces are constructed from European call and put options on the major European indices FTSE100, DAX30, CAC40, MIB40, and IBEX35. For the US market we take options on the S\&P500. Daily prices of all available options are obtained from Datastream. Following market practice, we use only out-of-the-money (OTM) options for the construction of the implied volatility surfaces, see CBOE (2003).

\section{Factor Decompositions of CDS Spreads and the Implied Volatility Surface}

\subsection{The Term Structure of CDS Spreads}

For each European market, we compute the term structure of CDS spreads. Since the CDS curves have similar properties as the yield curve, we can apply a well-established factor decomposition. Let us denote by $\left\{\ln C D S\left(t, \tau_{i}\right) ; i=1 \ldots N_{1}\right\}$ the time series of CDS spreads (in logarithms) for the available maturities. Using $\Delta x_{t}\left(\tau_{i}\right)=\ln C D S\left(t, \tau_{i}\right)-\ln \operatorname{CDS}\left(t-1, \tau_{i}\right)$, we can perform a principal component analysis decomposition as in Litterman and Scheinkman (1991). Table 1 contains the eigenvalues, computed using a one-year daily sample starting on $23 / 05 / 2007$ and expressed as a percentage of the total variance (see Da Fonseca and Gottschalk (2013) for an example of eigenvector shapes).

All CDS curves lead to the same decompositions, a result similar to that obtained for yield curve studies. The first eigenvector is always positive and corresponds to a shift of the CDS spread curve. Its associated eigenvalue dominates as it represents a large fraction of the global variance $185 \%$ on average among the five European countries). The second eigenvector implies a change of the slope because the short-term part is positive, whereas the long-term part is negative. The second eigenvalue accounts for $10 \%$ of the global variance on average. The third eigenvector has a U-shaped form and is related to a change of the convexity of the term structure. Similar to yield curve factor decompositions, the third eigenvalue only represents a very small fraction of the global variance (around 3\%). The overall results resemble what is obtained for yield curves in the sense that we get the usual level, slope and curvature factor decomposition. It is not necessary to go beyond the first three factors as together they explain $98 \%$ of market variance.

Table 1: Eigenvalues for the CDS factors as a percentage of the total variance

\begin{tabular}{|l|r|r|r|r|r|r|}
\hline & France & Germany & Italy & Spain & UK & 94.04 \\
\hline First eigenvalue & 76.18 & 88.98 & 83.09 & 80.54 & 94.56 \\
\hline Second eigenvalue & 18.62 & 8.11 & 8.97 & 12.05 & 4.04 & 10.36 \\
\hline Third eigenvalue & 2.99 & 2.39 & 3.61 & 4.52 & 1.57 & 3.02 \\
\hline Sum & 97.79 & 99.48 & 95.67 & 97.10 & 99.65 & 97.94 \\
\hline
\end{tabular}




\subsection{The Implied Volatility Surface}

To build an implied volatility surface on which we can apply a factor decomposition, we follow the approach developed in Cont and Da Fonseca (2002) and used in Da Fonseca and Gottschalk (2013). We denote by $C_{b s}\left(t, s_{t}, K, T, \sigma\right)$ the Black-Scholes formula for a European option (either call or put) at time $t$, with maturity $T$, strike price $K$, spot price $s_{t}$ and volatility $\sigma$ of the underlying asset. The implied volatilityfor an option whose market price is $c\left(t, s_{t}, K, T\right)$ is denoted by $\sigma_{b s, t}(T, K)$ and is the solution of the equation

$$
c_{b s}\left(t, s_{t}, K, T, \sigma_{b s, t}(T, K)\right)=c\left(t, s_{t}, K, T\right)
$$

As the Black-Scholes formula is monotonic with respect to volatility, this equation has a unique solution, and the function $\left\{\sigma_{b s, t}(K, T) ;(K, T)\right\}$ is called the implied volatility surface. We can parametrize this function in terms of time to maturity and moneyness $\left(m=K / s_{t}\right)$, so we define the function $I_{t}(m, \tau)=\sigma_{b s, t}\left(m s_{t}, t+\tau\right)$. As this surface is usually non-flat and exhibits a U-shaped form for all times to maturity with less convexity for long-term options, it is often referred to as the smile. The smile fluctuates over time.

All options sets lead to same-shaped factors as well as the same eigenvalue decomposition (see Da Fonseca and Gottschalk (2013) for an example). The eigenvalues (computed using a one-year daily sample starting on $23 / 05 / 2007$ and expressed as a percentage of the total variance) are presented in Table 2. Since the first eigensurface is always positive, it is associated with a translation or shift of the smile. As the first eigenvalue accounts for $75 \%$ of the global variance on average, we conclude that a one-factor model, based on this eigensurface, provides a reasonably good model for the dynamics of the smile. For a more accurate model we need to go beyond this first factor. The second eigensurface is, for all times to maturity, positive for moneyness lower than one and negative otherwise. A shock along this mode implies that out-of-the-money (OTM) put options, whose volatility is given by the smile with moneyness lower than one, will become more expensive. OTM call options, whose volatility is given by the smile with moneyness greater than one, will become less expensive. As a consequence, this eigensurface is associated with a bear market movement. The corresponding eigenvalue represents $17 \%$ of the total variance on average. This factor affects the skew of the smile. Lastly, the third eigensurface is associated with a bull market movement. A shock along this eigensurface implies a decrease of long-term implied volatility for all times to maturity, a strong increase of short-term OTM call prices and a lesser increase of short-term OTM put prices. Its eigenvalue is equal to around $5 \%$ of the total variance. As the first three eigenvalues account for $97 \%$ of the total variance, it is not necessary to go beyond these three factors.

\section{Table 2: Eigenvalues for the volatility factors as a percentage of the total variance}

\begin{tabular}{|l|r|r|r|r|r|r|}
\hline & CAC40 & DAX30 & MIB40 & IBEX35 & FTSE100 & Mean \\
\hline First eigenvalue & 84.18 & 77.52 & 71.34 & 74.73 & 67.48 & 75.05 \\
\hline Second eigenvalue & 8.16 & 14.08 & 17.04 & 19.64 & 25.44 & 16.87 \\
\hline Third eigenvalue & 5.91 & 6.18 & 5.32 & 2.94 & 4.09 & 4.89 \\
\hline Sum & 98.25 & 97.77 & 93.70 & 97.31 & 97.00 & 96.81 \\
\hline
\end{tabular}

We can now decompose the dynamics of the smile into these factors. We define the three scalar processes

We can now decompose the dynamics of the smile into these factors. We define the three scalar processes

$$
\Delta V O L_{k, t}=\sum_{j=1}^{N} \Delta X_{t}\left(\bar{m}_{j}, \bar{\tau}_{j}\right) e_{k}\left(\bar{m}_{j}, \bar{\tau}_{j}\right) ; k=1,2,3,
$$

which are the projection of the implied volatility change on the eigensurfaces, hence each one quantifies to which extent the smile "moves" along the direction given by the corresponding factor. Therefore, $\triangle V O L_{1, t}$ is associated with a shift of the smile, $\triangle V O L_{2, t}$ with a change of the skew (slope) of the smile, and $\triangle V O L_{3, t}$ with a change of the convexity of the smile. The principal component analysis relates the functions used to the covariance structure of the process. The factor decomposition allows us to reduce the dynamics of the smile, which is a surface, into three scalar time series that encompass most of the statistical properties. 


\section{Cross-Hedging Between Credit and Volatility Factors}

In this section, we focus on a regression analysis of the first factor (i.e. the main factor). More precisely, we regress the first volatility factor on a set of explanatory variables chosen among the credit factors. Since we have three credit factors, we perform three regressions. Also, we reverse the analysis by regressing the first credit factor on a set of volatility factors. These regressions are of practical interest as they allow us to devise cross-hedging strategies. The regressions are

$$
\begin{aligned}
& \Delta C D S_{1, t}=a+\sum_{k=1}^{N} b_{k} \Delta V O L_{k, t}+\varepsilon_{t}^{N, 1} \\
& \Delta V O L_{1, t}=\alpha+\sum_{k=1}^{N} \beta_{k} \Delta C D S_{k, t}+\varepsilon_{t}^{N, 2}
\end{aligned}
$$

with $N$ successively equal to $\{1,2,3\}$. The regression coefficients of these equations can be seen as hedging ratios. Of special importance is the adjusted $R^{2}$ of these regressions as it measures the effectiveness of the hedge.

Our approach is of interest for trading activities involving credit and volatility derivatives as the ratio computed in the regressions above can be used for the risk management of such portfolios of derivatives. Our work is in line with derivatives-oriented papers focusing on the credit-volatility relation; see, e.g., Carr and Wu (2007, 2010, 2011), and Carverhill and Luo (2011). The first two papers present consistent pricing frameworks for the two markets but are very challenging to implement. The third one proposes an equity derivative, the DOOM put, which mimics the CDS payoff. The last paper calibrates a threefactor intensity model on CDO quotes and analyses the interaction of these factors with factors driving the implied volatility surface. Our approach jointly analyses the entire implied volatility surface and the entire term structure of CDS spreads and is very simple to implement. As we have two subsamples, the first with the GFC and the second with the European sovereign debt crisis, we present the results separately.

\subsection{Credit-Volatility Disconnection During the GFC}

We first analyse the GFC period and report in Table 3 (lefthand side) the regressions for the US, the UK, France, and Spain for the period 23/05/2007-31/12/2009. All regressions lead to small $R^{2}$, no matter whether we consider the credit risk factor as dependent variable and the volatility factors as explanatory variables or the volatility factor as dependent variable and the credit risk factors as explanatory variables. To put our results in perspective with the literature, many studies find volatility, usually given by the ATM 1-month implied volatility, to be a rather good explanatory variable of credit risk, given by the 5-year CDS spread. For example, in Ericsson, Jacobs and Oviedo (2009), the regression of the change in the 5-year CDS spread on the change of equity volatility (computed as mean squared log returns), leads to an $R^{2}$ of $12 \%$. Most other studies analyse the level of the 5-year CDS spread and find volatility (either historical or implied) to be a significant explanatory variable with the regression $R^{2}$ rather high. Therefore, from our results we conclude that there is a disconnection between the credit market and the option market during the GFC.

Table 3: Cross-market factor regressions (23/05/2007 - 17/09/2012)

\section{\begin{tabular}{l|l}
$23 / 05 / 2007-31 / 12 / 2009$ & $01 / 01 / 2010-17 / 09 / 2012$
\end{tabular}}

\begin{tabular}{l|l}
$\begin{array}{l}\text { Dependent } \\
\text { Variable }\end{array}$ & Independent \\
Variables
\end{tabular}

(1) (2)

(3)

(1)

(2)

(3)

\begin{tabular}{|c|c|c|c|c|c|c|c|}
\hline \multirow[t]{4}{*}{$\Delta C D S_{1}$} & $\Delta V O L_{1}$ & 0.00 & 0.00 & -0.01 & $0.03^{* * *}$ & $0.01^{* * *}$ & $0.01^{* *}$ \\
\hline & $\Delta V O L_{2}$ & & 0.02 & 0.02 & & $0.10^{* * *}$ & $0.07^{* * *}$ \\
\hline & $\triangle V O L_{3}$ & & & $-0.12^{* *}$ & & & $-0.19^{* * *}$ \\
\hline & Adj. $R^{2}$ & 0.00 & 0.00 & 0.00 & 0.04 & 0.23 & 0.35 \\
\hline \multirow[t]{4}{*}{$\Delta V O L_{1}$} & $\Delta \mathrm{CDS}_{1}$ & -0.03 & -0.09 & -0.13 & $1.31^{* * *}$ & $1.10^{* * *}$ & $1.14^{* * *}$ \\
\hline & $\Delta \mathrm{CDS}_{2}$ & & $-1.02^{* *}$ & $-1.05^{* *}$ & & $-3.72^{* *}$ & $-3.54^{* *}$ \\
\hline & $\triangle C D S_{3}$ & & & -1.16 & & & 0.44 \\
\hline & Adj. $R^{2}$ & 0.00 & 0.00 & 0.01 & 0.04 & 0.05 & 0.05 \\
\hline
\end{tabular}

Panel A: United States 


\section{Panel B: United Kingdom}

\begin{tabular}{|c|c|c|c|c|c|c|c|}
\hline \multirow[t]{4}{*}{$\triangle C D S_{1}$} & $\triangle V O L_{1}$ & $0.05^{* * *}$ & $0.05^{* * *}$ & $0.04^{* * *}$ & $0.05^{* * *}$ & $0.04^{* * *}$ & $0.03^{* * *}$ \\
\hline & $\triangle V O L_{2}$ & & 0.02 & $0.05^{* *}$ & & $0.15^{* * *}$ & $0.13^{* * *}$ \\
\hline & $\triangle V O L_{3}$ & & & $-0.19^{* * *}$ & & & $-0.20^{* * *}$ \\
\hline & $\operatorname{Adj} . R^{2}$ & 0.03 & 0.03 & 0.05 & 0.11 & 0.20 & 0.25 \\
\hline \multirow[t]{4}{*}{$\triangle V O L_{1}$} & $\triangle C D S_{1}$ & $0.65^{* * *}$ & $0.66^{* * *}$ & $0.66^{* * *}$ & $2.10^{* * *}$ & $2.46^{* * *}$ & $2.47^{* * *}$ \\
\hline & $\triangle C D S_{2}$ & & -0.16 & -0.16 & & $-1.50^{* * *}$ & $-1.52^{* * *}$ \\
\hline & $\triangle C D S_{3}$ & & & 0.13 & & & -0.11 \\
\hline & $\operatorname{Adj} . R^{2}$ & 0.03 & 0.03 & 0.03 & 0.11 & 0.12 & 0.12 \\
\hline
\end{tabular}

\section{Panel C: France}

\begin{tabular}{|c|c|c|c|c|c|c|c|}
\hline \multirow{4}{*}{$\Delta C D S_{1}$} & $\triangle V O L_{1}$ & $0.05^{* * *}$ & $0.05^{* * *}$ & $0.04^{* * *}$ & $0.08^{* * *}$ & $0.18^{* * *}$ & $0.07^{* * *}$ \\
\hline & $\Delta V O L_{2}$ & & $0.07^{* * *}$ & $0.04^{*}$ & & $0.13^{* * *}$ & $0.11^{* * *}$ \\
\hline & $\triangle V O L_{3}$ & & & $-0.10^{* * *}$ & & & $-0.18^{* * *}$ \\
\hline & Adj. $R^{2}$ & 0.04 & 0.05 & 0.07 & 0.09 & 0.14 & 0.17 \\
\hline \multirow[t]{4}{*}{$\triangle V O L_{1}$} & $\triangle C D S_{1}$ & $0.87^{* * *}$ & $0.85^{* * *}$ & $0.87^{* * *}$ & $1.19^{* * *}$ & $1.18^{* * *}$ & $1.07^{* * *}$ \\
\hline & $\triangle C D S_{2}$ & & -0.39 & -0.33 & & 0.13 & 0.06 \\
\hline & $\triangle \mathrm{CDS}_{3}$ & & & -0.62 & & & $1.49 * *$ \\
\hline & $\operatorname{Adj} . R^{2}$ & 0.04 & 0.04 & 0.04 & 0.09 & 0.09 & 0.10 \\
\hline \multicolumn{8}{|c|}{ Panel D: Spain } \\
\hline \multirow[t]{4}{*}{$\triangle C D S_{1}$} & $\triangle V O L_{1}$ & $0.07^{* * *}$ & $0.07^{* * *}$ & $0.07^{* * *}$ & $0.11^{* * *}$ & $0.11^{* * *}$ & $0.11^{* * *}$ \\
\hline & $\triangle V O L_{2}$ & & 0.03 & 0.03 & & -0.02 & -0.02 \\
\hline & $\triangle V O L_{3}$ & & & $-0.11^{* *}$ & & & $0.11^{* *}$ \\
\hline & $\operatorname{Adj} . R^{2}$ & 0.06 & 0.06 & 0.07 & 0.14 & 0.14 & 0.15 \\
\hline \multirow[t]{4}{*}{$\triangle V O L_{1}$} & $\triangle C D S_{1}$ & $0.89^{* * *}$ & $0.88^{* * *}$ & $0.88^{* * *}$ & $1.36^{* * *}$ & $1.39 * * *$ & $1.00^{* * *}$ \\
\hline & $\triangle C D S_{2}$ & & -0.38 & -0.38 & & $0.83^{*}$ & -0.80 \\
\hline & $\triangle \mathrm{CDS}_{3}$ & & & -0.07 & & & $3.94^{* * *}$ \\
\hline & $\operatorname{Adj} . R^{2}$ & 0.06 & 0.06 & 0.06 & 0.14 & 0.15 & 0.17 \\
\hline
\end{tabular}

Note: Regression intercepts have been suppressed in order to conserve space. The symbol *** denotes statistical significance at the $1 \%$ level, ${ }^{* *}$ at the $5 \%$ level, and * at the $10 \%$ level. 
This is problematic because from a theoretical point of view credit risk and volatility are closely related. This is one of the main messages of Merton (1974) and the subsequent extensions, Black and Cox (1976) and Huang and Huang (2012). Because of this relation equity options can be used (and are in fact used in practice) to hedge credit risk. However, our results underline the fact that the hedge is likely to perform poorly and that a short credit risk trader might suffer heavy losses. Even though credit risk and equity volatility both increased during the GFC, there was a breakdown of the intrinsic relationship between these markets when in theory the relation should have prevailed during the crisis.

Our result is potentially worrying for the following reason. From a risk management point of view, the connection between credit and equity markets is the basis for all crosshedging strategies. This is particularly true at a portfolio or aggregate level, and our results illustrate the fact that it might be impossible to manage risk. One could argue that the entities in the credit market and those in the equity index market are not the same, thereby explaining the failure of this connection. However, we work at the highest possible level, the index level. Note that the regression coefficients are significant, hence a correlation between the factors exists, but the $R^{2}$ which indicate the effectiveness of the hedge are small.

\subsection{Credit-Volatility Connection During the European Debt Crisis}

We now focus on the second subsample and report in Table 3 (right-hand side) the regression results for the European markets for the period 01/01/2010 - 17/09/2012. All regressions now lead to higher $R^{2}$, meaning that the CDS-volatility relation is reasonably good in the second subsample. When we look at how the first credit risk component can be hedged using the volatility factors, we observe that with only the first volatility factor we can achieve an average (among European countries) $R^{2}$ of $13.4 \%$, more than three times the result obtained in the first subsample. Important is the fact that during this period the Italian and Spanish CDS markets entered into the sovereign debt crisis and, therefore, experienced a significant increase of their CDS spreads, as shown in Figure 4. Consequently, even when the CDS and volatility markets are volatile, they can still be connected. This aspect is crucial from a hedging point of view as underlined before.

From these results we can also ascertain the impact of lower volatility factors. Adding two volatility factors leads to an average $R^{2}$ of $22.6 \%$. If we take into account the fact that we work with changes in the dependent variable, this is a very good result. The third factor, whose eigenvalue is very small, increases the $R^{2}$ by $3.4 \%$. The second factor significantly improves the quality of the regressions for the UK (and also for Germany), increasing the $R^{2}$ by $10 \%$. Its impact for France (and also for Italy) is small, improving the $R^{2}$ by $5 \%$, whilst for Spain adding factors beyond the first one does not improve the $R^{2}$ at all. However, the $R^{2}$ is still significantly higher than what we obtain during the GFC.

For the US market, for this second subsample we can draw the following conclusions. Contrarily to the European market the first volatility factor leads to an $R^{2}$ of $4 \%$, which is quite low. Interestingly, the second volatility factor increases the $R^{2}$ by $19 \%$, which is a huge improvement. Lastly, the third factor adds $12 \%$ to the $R^{2}$, in contrast to the European results. This case also underlines the importance of lowerorder factors despite their small eigenvalue in the spectral decomposition. Furthermore, it has a profound impact on the choice of the number of factors because our results suggest that, if we wanted to work with a consistent model, we would need a three-factor model.

We now analyse the regressions of the volatility factor on the credit factors and start with the European countries. In this case the situation is rather different. The second and third credit factors do not improve the regressions for any of the countries as the $R^{2}$ remain virtually unchanged after the addition of these factors. The first credit factor allows us to obtain a low $R^{2}$ of $9 \%$ for France, but an average $R^{2}$ of $14.5 \%$ for the other countries. This is clearly an improvement compared with the earlier subsample. What is also important to note is that Spain and Italy experienced the turmoil of the sovereign debt crisis during that period and still, the connection between the credit and volatility markets was intact. For the US, the results are similar in the sense that adding factors does not improve the $R^{2}$ and, in contrast with the European markets, the first volatility factor leads to an $R^{2}$ as low as $4 \%$.

In conclusion, the hedge of the credit factor using volatility factors can be effective and lower-order factors improve the quality of the hedge (as represented by the adjusted $R^{2}$ ) significantly. The hedge of the volatility factor using credit factors cannot be improved beyond the first credit factor but the results are reasonably good. Two important conclusions emerge from these results. The GFC led to a breakdown of the relationship between the credit market and the volatility market, jeopardizing any attempt to perform credit-volatility cross-hedges during that period. However, this relation can be effective during a crisis as the Italian and Spanish markets show during the second subsample covering the sovereign debt crisis. 
The results also underline the importance of including higher modes although the associated eigenvalues might be small. Improved explanatory power is found in regressions of both the first CDS factor on volatility factors and the first volatility factor on CDS factors, although our results suggest that the CDS market can be hedged more effectively with the volatility market than vice versa. The $R^{2}$ increase between twofold and elevenfold when comparing the second to the first subsample. This is interesting insofar as the findings apply to all countries across the board, no matter whether they were severely affected by the European debt crisis (like Spain and Italy) or barely affected (like Germany and the UK). We conclude that depending on the nature of the crisis the CDS-volatility relation can vanish.

\subsection{Analysis of Intra-Market Linkages}

During the GFC there was a breakdown of the relationship between the credit and the volatility markets both in the US and Europe. As this was a global crisis, we wonder to which extent the European credit and volatility markets were connected to the US markets. To quantify this relation we restrict ourselves to the first credit and volatility factors and perform regressions of these factors on the first US credit and volatility factors separately during the GFC. From a mathematical point of view for the credit factors we perform the regressions

$$
\begin{aligned}
& \triangle C D S_{1, t}^{\text {Eur }}=a+b_{1} \Delta V O L_{1, t}^{U S}+\varepsilon_{t}^{C V} \\
& \Delta C D S_{1, t}^{\text {Eur }}=\alpha+\beta_{1} \Delta C D S_{1, t}^{U S}+\varepsilon_{t}^{C C}
\end{aligned}
$$

These allow us to determine if the European credit factors can be hedged using either the US volatility factor (5) or the US credit factor (6). Similarly, for the volatility factors we carry out the regressions

$$
\begin{aligned}
& \Delta V O L_{1, t}^{E u r}=a+b_{1} \Delta V O L_{1, t}^{U S}+\varepsilon_{t}^{V V} \\
& \Delta V O L_{1, t}^{E u r}=\alpha+\beta_{1} \Delta C D S_{1, t}^{U S}+\varepsilon_{t}^{V C}
\end{aligned}
$$

The results for these regressions are reported in Table 4. For the European credit factors regressed on the US volatility factor and for the European volatility factors regressed on the US credit factor we obtain similar results. Namely, the adjusted $R^{2}$ is very small (less than $2 \%$ ), thus implying a poor credit-volatility market linkage. This is not a surprise as we cannot expect these relationships to be stronger than the relationship between the credit market and the volatility market within the same country, which is known to be weak for this subsample (see the previous sections of this paper). More interesting is the intra-market analysis, that is the relation between the US and European credit market (volatility market). The regressions of the European credit factors on the US credit factor result in high $R^{2}$ (on average $19.6 \%$ ). Similarly, for the volatility market we obtain an average $R^{2}$ of $22 \%$. Compared with the cross-hedge $R^{2}$ of the previous subsection the improvement is significant. The implication is that, during the GFC, the hedge of a European CDS (volatility) position could have been more effective using the US CDS (volatility) market than using the European volatility (CDS) market. The same applies to a US CDS position, which could have been hedged using the European CDS markets.

Table 4: Cross-market and cross-country factor regressions (23/05/2007 - 31/12/2009)

\section{United Kingdom}

(1)
(2)

\section{France}

(1)
(2)
Spain

(1)
(2)

\section{Panel A: Dependent Variable $\triangle C D S$}

$$
\Delta C D S_{1, U S}
$$

$0.36^{* * *}$

$\triangle V O L_{1, U S}$

Adj. $R^{2}$

Panel B: Dependent Variable $\triangle V O L_{1}$

\section{$\triangle C D S_{1, U S}$}

$\triangle V O L_{1, U S}$

Adj. $R^{2}$
$0.32^{* * *}$

0.02
$0.20 * * *$

$0.36^{* * *}$

0.00

0.00
0.00

0.00
0.01

0.18
$0.19^{* * *}$

$0.52^{* * *}$

0.31

0.01
$0.45^{* * *}$

0.29
$0.40^{* * *}$

0.25

Note: In Panel A, each country's first CDS factor is regressed on the United States' first CDS and volatility factor. In Panel $B$, each country's first volatility factor is regressed on the United States' first CDS and volatility factor. Regression intercepts have been suppressed in order to conserve space. The symbol *** denotes statistical significance at the $1 \%$ level, ** at the $5 \%$ level, and * at the $10 \%$ level. 


\section{Conclusion}

In this work we propose a joint analysis of the term structure of credit default swap spreads and the implied volatility surface. Using the methodology developed in Da Fonseca and Gottschalk (2013), we develop a factor decomposition for both markets which allows us to study them globally, i.e. the entire term structure of CDS spreads and the entire implied volatility surface. We implement our methodology on a database of options and CDS spreads for five European countries and the United States in a sample covering both the Global Financial Crisis and the European sovereign debt crisis (2007-2012). The factor decompositions for the implied volatility surface and the CDS curve allow us to handle the joint statistical properties of the two markets.

To quantify how crises affect the relationship between the credit and volatility markets we perform a regression analysis which underlines the cross-hedging opportunities between the two markets. We find that during the European debt crisis the connection between the credit and volatility markets is rather good albeit some of the counstries (Spain and Italy) experienced severe turmoil over this period. During the GFC there is a clear breakdown of the relationship between the two markets for all countries. Robustness checks with US data confirm these results. Consistently with Da Fonseca and Gottschalk (2013) we find that the relation is not reciprocal, i.e. credit factors can be hedged more effectively using volatility factors than vice versa. Moreover, factors with small eigenvalues can be very important from a cross-hedging point of view; this has far-reaching consequences from a risk management perspective as the number of factors chosen for a model should not depend only on the eigenvalue decomposition.

\section{References}

Benkert, C. (2004), Explaining credit default swap premia. Journal of Futures Markets 24(1), 71-92.

Black, F. and Cox, J. C. (1976), Valuing corporate securities: some effects of bond indenture provisions. Journal of Finance 31 (2), 351-367.

Cao, C., Yu, F., and Zhong, Z. (2010), The information content of option-implied volatility for credit default swap valuation. Journal of Financial Markets 13(3), 321-343.

Cao, C., Yu, F., and Zhong, Z. (2011), Pricing credit default swaps with option-implied volatility. Financial Analysts Journal 67(4), 67-76.

Carr, P. and WU, L. (2007), Theory and evidence on the dynamic interactions between sovereign credit default swaps and currency options. Journal of Banking and Finance 31 (8), 2383-2403.

Carr, P. and WU, L. (2010), Stock options and credit default swaps: a joint framework for valuation and estimation. Journal of Financial Econometrics 8(4), 409-449.

Carr, P. and Wu, L. (2011), A simple robust link between American puts and credit protection. Review of Financial Studies 24(2), 473-505.

Carverhill, A. P. and Luo, D. (2011), Pricing and integration of the CDX tranches in the financial market. Working PaperSSRN-1786574.

CBOE (2003), The CBOE Volatility Index - VIX, http://www.cboe.com/micro/vix/vixwhite.pdf.

Collin-Dufresne, P., Goldstein, R. S., and Yang, F. (2012), On the relative pricing of long-maturity index options and collateralized debt obligations. Journal of Finance 67(6), 1983-2014.

Cont, R. and Da Fonseca, J. (2002), Dynamics of implied volatility surfaces. Quantitative Finance 2(1), 45-60.

Cremers, M., Driessen, J., Maenhout, P., and Weinbaum, D. (2008), Individual stock-option prices and credit spreads. Journal of Banking and Finance 32(12), 2706-2715.

Da Fonseca, J. and Gottschalk, K. (2013), A joint analysis of the term structure of credit default swap spreads and the implied volatility surface. Journal of Futures Markets 33(6), 494-517. 
Da Fonseca, J. and Gottschalk, K. (2014), Cross-hedging strategies between CDS spreads and option volatility during crises. Journal of International Money and Finance. http://dx.doi.org 10.1016/j.jimonfin.2014.03.010.

Ericsson, J., Jacobs, K., and Oviedo, R. (2009), The determinants of credit default swap premia. Journal of Financial and Quantitative Analysis 44(1), 109-132.

Forte, S. and Pena, J. I. (2009), Credit spreads: an empirical analysis on the informational content of stocks, bonds, and CDS. Journal of Banking and Finance 33(11), 2013-2025.

Han, B. and Zhou, Y. (2011), Term structure of credit default swap spreads and cross-section of stock returns. Working Paper-SSRN-1735162.

Huang, J.-Z. and Huang, M. (2012), How much of the corporate-treasury yield spread is due to credit risk? Review of Asset Pricing Studies 2(2), 153-202.

Hui, C.-H. and Chung, T.-K. (2011), Crash risk of the euro in the sovereign debt crisis of 2009-2010. Journal of Banking and Finance 35(11), 2945-2955.

Litterman, R. and Scheinkman, J. (1991), Common factors affecting bond returns. Journal of Fixed Income 1(1), 54-61. Merton, R. (1974), On the pricing of corporate debt: the risk structure of interest rates. Journal of Finance 29(2), 449470 .

\section{Note:}

'This article is based on Da Fonseca and Gottschalk (2014).

\section{Corresponding Author:}

Katrin Gottschalk is a Senior Lecturer in Finance at the Auckland University of Technology, Private Bag 92006, New Zealand. Email katrin.gottschalk@aut.ac.nz 